\title{
Potential grazing effects in incubations with ${ }^{14} \mathrm{C}$
}

\author{
John Marra $^{1, *}$, Elisa Capuzzo ${ }^{2,4}$, Vivian Montecino ${ }^{3}$ \\ ${ }^{1}$ Aquatic Research and Environmental Assessment Center, Brooklyn College of the City University of New York, Brooklyn, \\ New York 11210, USA \\ ${ }^{2}$ Edinburgh Napier University, Edinburgh EH14 1DJ, UK \\ ${ }^{3}$ Department of Ecological Sciences, Faculty of Sciences, Universidad de Chile, Santiago 3425, Chile \\ ${ }^{4}$ Present address: Centre for Environment, Fisheries and Aquaculture Science (CEFAS), Lowestoft NR33 OHT, UK
}

\begin{abstract}
We conducted experiments to assess the importance of heterotrophic activities (i.e. grazing) in primary production incubations with ${ }^{14} \mathrm{C}$. Carbon assimilation over 12 and $24 \mathrm{~h}$ was measured in whole seawater and in samples that had been diluted with filtered seawater to various concentrations, in surface samples taken from the Gulf of Aqaba (Israel) in April 2008. Carbon assimilation was higher in the diluted samples by about $20 \%$, suggesting that carbon assimilation in undiluted seawater samples is affected by grazing at time scales of $1 \mathrm{~d}$ or less. The difference between the diluted and undiluted samples was, however, statistically not significant. Nevertheless, incubations with ${ }^{14} \mathrm{C}$ lasting 12 to $24 \mathrm{~h}$ may at times be affected by grazing loss.
\end{abstract}

KEY WORDS: Grazing $\cdot$ Assimilation $\cdot$ Incubation $\cdot$ Dilution $\cdot$ Heterotrophy

\section{INTRODUCTION}

Over the last few decades, several means for isolating phytoplankton for ${ }^{14} \mathrm{C}$-based photosynthesis studies have been developed. These include track autoradiography (Knoechel \& Kalff 1976, Iturriaga \& Marra 1988), the isolation of single cells after incubation (Rivkin \& Seliger 1981), and the separation of populations using flow cytometry (Li 1994). In a separate development, Landry \& Hassett (1982) introduced the 'dilution method' as a means to understand the growth and grazing loss in natural populations. In a dilution experiment, seawater samples are combined with particle-free seawater in a series of ratios, such that the fraction of unfiltered seawater varies from e.g. 0.1 to 1.0 in a series. Dilution of the original sample, therefore, can distinguish activities that are dependent on encounters between cells, and therefore biomass-dependent (e.g. grazing), from those activities that are properties of the cells themselves (e.g. photosynthesis). Encounter rates, or grazing, depend on how much the sample is diluted, while photosynthesis of the cells remains unchanged. After a specified time, the change in phytoplankton biomass (e.g. cell numbers, chlorophyll a [chl a] concentration) is plotted against the fraction of unfiltered seawater, or dilution. Freed from grazing pressure at high dilution, while more subject to grazing at minimal or no dilution, the change in biomass is expected to be a linear, decreasing, function of the fraction (0 to 1) of raw seawater. Phytoplankton growth is assumed to be identified at $100 \%$ dilution, or, in a plot of phytoplankton biomass change ( $y$-axis) against dilution ( $x$-axis), the $y$-axis intercept. The (negative) slope of the relationship between the change in phytoplankton biomass and the dilution is an estimate of the loss to grazing.

Landry \& Hassett's (1982) dilution method has become widely adopted in the analysis of plankton communities in many types of environments (e.g. Gifford et al. 1995), and accompanied by critical analysis (e.g. Gallegos 1989, Worden \& Binder 
2003). The method does not always give results in accordance with expectations (Lessard \& Murrell 1998, Worden \& Binder 2003). The corresponding ${ }^{14} \mathrm{C}$ methods (single-cell isolation, track autoradiography, flow cytometry of labeled populations) have not entered into wide use, largely for technical reasons (e.g. isotopic contamination in flow cytometers; timeconsuming and tedious). Nevertheless, the 2 general approaches, dilution and single-cell analysis, have in common the isolation of phytoplankton metabolism from heterotrophic processes (in the case of dilution, as long as dilution is sufficient), affording a means to study the metabolism of natural phytoplankton populations.

The dilution method has rarely been used in combination with ${ }^{14} \mathrm{C}$. We have found only 2 reports: Geider (1988) for experiments during a spring bloom in temperate waters (Celtic Sea), and Gallegos \& Vant (1996) for experiments conducted in a turbid harbor (Secchi depth: <0.5 to $1.4 \mathrm{~m}$ ). We extend these observations to oligotrophic conditions that might experience higher levels of heterotrophic activity. Thus, like those authors, we conducted experiments that represent a combination of ${ }^{14} \mathrm{C}$ uptake and the dilution method. We diluted seawater samples with filtered seawater from the same location, which we inoculated with ${ }^{14} \mathrm{C}$ and incubated. The incubations were stopped at 12 and $24 \mathrm{~h}$, meaning that we could measure both photosynthetic uptake and overnight loss. The goal of these experiments was to test whether the ${ }^{14} \mathrm{C}$ method is affected by grazing, and therefore whether it estimates net primary production or something closer to net community production (Marra 2009). Net primary production is measured as the difference between gross production and autotrophic respiration. To the extent that grazing, and therefore heterotrophic respiration, contributes to the measurements, ${ }^{14} \mathrm{C}$ assimilation can approximate net community production.

Differences between net primary and net community production, as measured by the ${ }^{14} \mathrm{C}$ method, may be small (Laws 1984, Laws et al. 2000); see 'Discussion'. We are motivated, however, by the lack of empirical evidence to support that supposition. Moreover, if the ${ }^{14} \mathrm{C}$ method approximates net primary production, it would satisfy one of the assumptions that permit the calculation of phytoplankton respiration (Marra \& Barber 2004). Marra \& Barber (2004) provided empirical support for the idea that phytoplankton respiration could be estimated from the overnight loss of ${ }^{14} \mathrm{C}$ in incubated samples. The idea depends on 3 assumptions: (1) ${ }^{12} \mathrm{C}$ and ${ }^{14} \mathrm{C}$ are metabolically well mixed within a phytoplankton cell after
$12 \mathrm{~h},(2)$ daytime autotrophic respiration is equal to that occurring at night, and (3) ${ }^{14} \mathrm{C}$ assimilation from dawn to dusk approximates net primary production. If these 3 assumptions can be accepted, autotrophic respiration can be calculated as the overnight loss of ${ }^{14} \mathrm{C}$ divided by the fraction of day length (Marra \& Barber 2004).

Here, we report results from one of the experiments conducted by 3 members of the Phytoplankton Group at the GAP 2008 workshop, held at the InterUniversity Institute (IUI) in Aqaba, Israel, in April 2008.

\section{MATERIALS AND METHODS}

We used the laboratory facilities at the IUI. Nearsurface $(\sim 5 \mathrm{~m})$ pre-dawn water samples were collected from stations in the Gulf of Aqaba (Eilat), as reported by Iluz et al. (2009). For logistical reasons, seawater to create the dilution series occasionally was from collections several hours prior to the sample collection time.

To create the dilution series, seawater was filtered (by gravity) through a sandwich of 2 filters: the first, a glass fiber filter (corresponding in characteristics to a $\mathrm{GF} / \mathrm{F}$ ), and the second, a Millipore HA (pore size: $0.45 \mu \mathrm{m})$. The filtered seawater was added to sterile tissue culture flasks $(270 \mathrm{ml})$ such that subsequently filling them with raw seawater resulted in a dilution series of $100,46,26$, and $5.6 \%$ raw seawater. We also used filtered seawater as a blank, which was handled in the same way as the dilution series.

A word about the efficacy of our filtration: Kim et al. (2006) used the difference between material captured by a $0.45 \mu \mathrm{m}$ nominal pore-size filter (Millipore HA) and a $0.7 \mu \mathrm{m}$ nominal pore-size filter $(\mathrm{GF} / \mathrm{F})$ to represent the bacterial fraction. Thus, it is likely that the filter set that we used effectively removed the bacteria from the water used for dilution. However, Torrella \& Morita (1981) demonstrated that small cells of heterotrophic bacteria occurred in seawater, and first used the term 'ultramicrobacteria' (UMB) to define those smaller than $0.45 \mu \mathrm{m}$. The UMB they found grew very slowly even under nutrient-rich conditions. Other evidence for the occurrence and growth of UMB is in MacDonell \& Hood (1982) and Li \& Dickie (1985). UMB may have been present in our samples, but it is difficult to imagine how they might have fixed significant inorganic carbon or taken up excreted organic carbon in the samples containing only filtered seawater. And even so, we have subtracted the filtered 
seawater 'blank' from the assimilation values according to the dilution factor. Our filter methods will not have removed viruses (see 'Discussion').

A nominal $5 \mu \mathrm{Ci}$ of ${ }^{14} \mathrm{C}$ as $\mathrm{NaHCO}_{3}$ was added to 6 replicates for each dilution. Before dawn on the day of each experiment, the samples were placed in a water table continuously supplied with surface seawater for cooling. Screening reduced the incident light to $50 \%$ surface irradiance. At dusk, 3 replicates from each dilution were removed for assay, and the remaining 3 removed from the incubator just prior to the next dawn, so that 12 and $24 \mathrm{~h}$ carbon assimilation rates were measured.

The total counts added to the samples were determined on subsamples $(1 \mathrm{ml})$ from the incubation flasks, which were placed in scintillation vials that had $0.5 \mathrm{ml}$ of $\beta$-phenethylamine. ${ }^{14} \mathrm{C}$ in the particulate matter was assayed by filtering the samples onto GF/F filters. The filters were placed in scintillation vials that were then placed in a fume hood. A volume of $0.5 \mathrm{ml}$ of $50 \% \mathrm{HCl}$ was added to each vial and the vials allowed to remain in the hood for $12 \mathrm{~h}$ to remove inorganic ${ }^{14} \mathrm{C}$. Scintillation fluor $(12 \mathrm{ml})$ was added to the vials, and after an additional $24 \mathrm{~h}$, the vials were counted in a scintillation counter (Packard 3255) for 10 min each.

Carbon assimilation in the samples was calculated as the average uptake minus the average uptake in the filtered seawater control (corrected by the dilution percentage). Autotrophic respiration was calculated as the difference between the 12 and $24 \mathrm{~h}$ uptake rates divided by 0.5 (i.e. 12 h/24 h) (Marra \& Barber 2004).

\section{RESULTS}

We completed experiments on 2 and 4 April 2008 (Expts 1 \& 2, respectively). The filtered seawater values for Expts 1 and 2 averaged 208 and 1248 disintegration per minute $(\mathrm{dpm} ; 2$ to $5 \%$ of the dpm in raw seawater), respectively.

Background data have been presented in Iluz et al. (2009), and can be consulted for details regarding hydrographic conditions, biomass levels, and environmental properties. The GAP investigators in the Phytoplankton Group (Iluz et al. 2009) observed a short-lived bloom of diatoms in response to a brief wind-mixing event, the indicators of which are summarized in Table 1.

Between 1 and 3 April, diatom biomass had increased from 1 to $23 \mu \mathrm{g} \mathrm{C}{ }^{-1}$ and thereafter declined. Near-surface chl a levels remained between $\sim 0.5$ and $\sim 0.7 \mu \mathrm{g} \mathrm{l^{-1 }}$. Dissolved inorganic nitrogen also changed, increasing from $0.01-0.02$ to $0.8-1.0 \mu \mathrm{M} N$ on 2 April, and declining thereafter. A contemporaneous measurement of daily primary production reported by Iluz et al. (2009) for 2 April, at $35 \mathrm{mg} \mathrm{C} \mathrm{m}^{-3} \mathrm{~d}^{-1}$, is within $10 \%$ of the value reported here ( $24 \mathrm{~h}$ incubations).

Fig. 1 shows the results of Expts 1 and 2, presented as uptake as a function of dilution. The error bars in all figures are the $95 \%$ confidence limits. (The standard errors of the mean carbon assimilation values were $<10 \%$.) The linear regression is shown of the average $\mathrm{C}$ uptake for the diluted samples, assuming the filtered seawater value is zero. The regression coefficient is the value extrapolated to the undiluted sample $(x=1$, or $100 \%$ raw seawater) for comparison. The regression coefficients show that the diluted samples predict a slightly higher value for carbon assimilation in the undiluted samples. The difference is measurable, but given the error in the regression, not significantly different than the uptake in the undiluted samples.

Phytoplankton respiration, estimated according to Marra \& Barber (2004), is also shown in Fig. 1. The rates of phytoplankton respiration follow those of carbon assimilation. And, as in the carbon assimilation, respiration declines relative to what would have been expected from the diluted samples.

\section{DISCUSSION}

There is a measurable difference between the diluted and undiluted samples with regard to carbon 


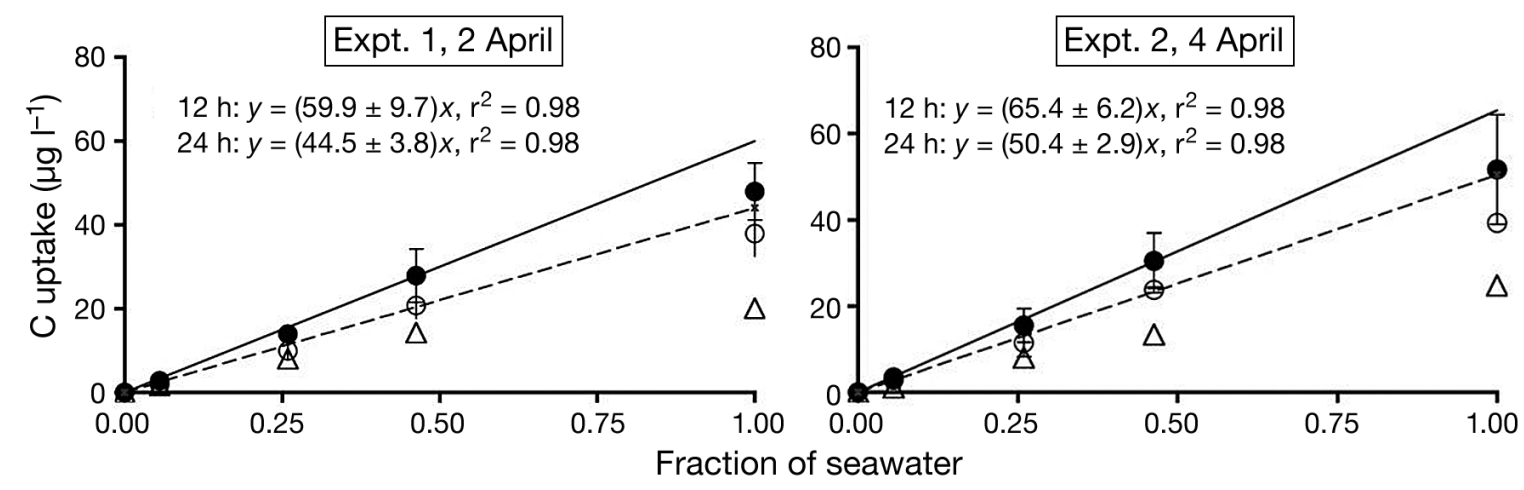

Fig. 1. Averaged carbon assimilation over $12 \mathrm{~h} \mathrm{( \bullet )} \mathrm{and} 24 \mathrm{~h}(\mathrm{O})$. Error bars are the $95 \%$ confidence limits. Lines represent the regression slope of the carbon assimilation rates in the diluted samples for $12 \mathrm{~h}$ (solid line) and $24 \mathrm{~h}$ (dashed line). The equations for the regression lines and the coefficient of determination $\left(\mathrm{r}^{2}\right)$ are indicated on the figure, with the errors in the slope given as the $95 \%$ confidence limit. Estimates of phytoplankton respiration $(\Delta)$ are calculated as the overnight carbon loss (dawn-to-dusk uptake minus $24 \mathrm{~h}$ uptake) multiplied by 24/12

assimilation over 12 and $24 \mathrm{~h}$. The measured differences are not significant, statistically. If the diluted samples had less ${ }^{14} \mathrm{C}$ activity than the undiluted, then we might conclude a methodological error had occurred in diluting the samples and somehow adversely affecting carbon assimilation. The fact that the diluted samples are higher suggests that we can compare the dilutions in terms of ${ }^{14} \mathrm{C}$ assimilation.

The most likely difference between the diluted and undiluted samples is loss to grazing (Landry \& Hassett 1982, Jackson 1983). As stated above (see 'Introduction'), we are aware of only 2 publications that have conducted similar experiments, and in very different environments from the Gulf of Aqaba. Geider (1988) showed equivalent values, over $12 \mathrm{~h}$, in undiluted samples and samples that had been diluted with particle-free ambient seawater (10 and $25 \%$ raw seawater). Gallegos \& Vant (1996) reported diluting their samples to 5 to $10 \%$ in order to isolate phytoplankton growth and thereby estimate carbon:chl a ratios. Our results are similar to Geider (1988) in that we show statistically equivalent carbon assimilation, whether the samples are diluted or not (Fig. 1).

The statistical equivalence of diluted and undiluted samples means either that microzooplankton grazing matters little as a loss factor in incubations, or else the ${ }^{14} \mathrm{C}$ method, as typically practiced, is insensitive to the activities of microzooplankton. That grazing is a minor loss is one conclusion of Joint \& Pomroy (1983), who observed little transfer of the isotopic label from small $(0.2$ to $1 \mu \mathrm{m})$ to larger size fractions $(>5 \mu \mathrm{m})$ in time-course experiments. Dilution experiments, however, indicate that micro-grazers can crop, on average, $>60 \%$ (Calbet
\& Landry 2004), and at least $50 \%$ (Dolan \& McKeon $2005)$ of daily primary production. At the same time, Laws (1984), and in this context, Laws et al. (2000), concluded, theoretically, that the measured impact of grazing on a productivity determination using ${ }^{14} \mathrm{C}$ is minor. To the extent that viruses are important, and for these measurements, any viruses in the samples can be considered 'grazers' and would have the most effect in the undiluted samples. Wilhelm \& Suttle (1999) said that viruses may lyse 2 to $10 \%$ of phytoplankton cells per day. Then, too, they might also affect microzooplankton grazers. Given these considerations, we conclude that viral attack is within the error of our measurements.

According to Laws et al. (2000), the effect of grazing can be written as the respiration of microzooplankton $(r)$, and a term $(\beta)$ describing the relationship between phytoplankton growth $(\mu)$ and zooplankton grazing $(g)$ :

where

$$
1-r(1-\beta)
$$

$$
\beta=[(\mu-g) / \mu)]\left[\left(\mathrm{e}^{\mu t}-1\right) /\left(\mathrm{e}^{\mu t}-\mathrm{e}^{g t}\right)\right]
$$

and where $t$ is time. Respiration can be considered directly dependent on grazing (ingestion) (Verity 1985, and references therein), which simplifies the above relationships. Accordingly, grazing will decrease carbon fixation into phytoplankton by 2 to $15 \%$ over phytoplankton growth rates of 0.2 to $1.4 \mathrm{~d}^{-1}$. Therefore, the difference between carbon assimilation in diluted versus undiluted incubations should be small, in agreement with what we have found in the present experiments.

The experiments here and elsewhere (e.g. Geider 1988) suggest that the dominant processes occurring 
in incubations are photosynthesis and autotrophic respiration. We did not keep track of chl a concentrations during the incubations, and that might limit our interpretation. On the other hand, chl a can vary as an adaptation response, or with growth, in addition to being subject to grazing. Indications from parallel fluorescence kinetics measurements suggest that chl a did not change significantly from the initiation of the incubations to the following dawn (J. Kohler pers. comm.).

A major assumption of the dilution method (Landry \& Hassett 1982) is that grazing is a linear function of dilution, and there are situations where this might not be the case. Grazing, as a function of phytoplankton biomass, may be zero below a threshold of prey biomass, and it may saturate at high biomass (Gallegos 1989, Evans \& Paranjape 1992, Worden \& Binder 2003). The experiments must assume that there is no mortality of grazers during the incubation (Dolan \& McKeon 2005). Both of these effects will tend to increase the negative slope of biomass change as a function of dilution, and therefore overestimate grazing. Saturated feeding would mean that grazing might be the same regardless of dilution, and not important in any case. It is hard to imagine, however, that zooplankton would still be food-saturated at $5.6 \%$ dilution of natural seawater concentrations. The rates at this dilution percentage were not significantly different from those at higher biomass concentrations, although the confidence intervals are larger. If grazers are not food-limited, then we can expect 'bottom-up' regulation of phytoplankton biomass, and grazing is therefore not driving ecosystem functioning.

Classically, phytoplankton respiration has been thought to be 10 to $20 \%$ of gross primary production (GPP) (Parsons et al. 1984). More recent analyses have put its value higher, at 30 to $40 \%$ of GPP (Langdon 1993, Laws et al. 2000, Robinson \& Williams 2005). Phytoplankton respiration in the present study is estimated to be 30 to $50 \%$ of GPP, based on the calculation procedure in Marra \& Barber (2004). A recent report found that small phytoplankton may be facultative heterotrophs, ingesting significant numbers of bacteria (Zubkov \& Tarran 2008). If so, then this also supports the higher estimates of phytoplankton respiration. As for carbon assimilation, respiration is lower in the undiluted samples compared to what would have been expected from the diluted samples. We conclude that the lower respiration is because grazing has cropped phytoplankton biomass in the undiluted samples.
Acknowledgements. We were very fortunate to have the assistance of N. Stambler for logistics and laboratory set-up, and J. Silverman for sampling and background information on the Gulf of Aqaba. We thank D. Iluz for help with laboratory procedure. V.M.'s attendance at the GAP 2008 workshop was partially supported by a grant from the Universidad de Chile. We thank I. Berman-Frank and T. Berman for the invitation to participate in GAP 2008, and for their considerable organizational skills.

\section{LITERATURE CITED}

Calbet A, Landry MR (2004) Phytoplankton growth, microzooplankton grazing, and carbon cycling in marine systems. Limnol Oceanogr 49:51-57

> Dolan JR, McKeon K (2005) The reliability of grazing rate estimates from dilution experiments: Have we overestimated rates of organic carbon consumption by microzooplankton? Ocean Sci 1:1-7

> Evans GT, Paranjape MA (1992) Precision estimates of phytoplankton growth and microzooplankton grazing when the functional response of grazers may be nonlinear. Mar Ecol Prog Ser 80:285-290

Gallegos CL (1989) Microzooplankton grazing on phytoplankton in the Rhode River, Maryland: nonlinear feeding kinetics. Mar Ecol Prog Ser 57:23-33

Gallegos CL, Vant WN (1996) An incubation procedure for estimating carbon-to-chlorophyll ratios and growthirradiance relationships of estuarine phytoplankton. Mar Ecol Prog Ser 138:275-291

Geider RJ (1988) Estimating the growth and loss rates of phytoplankton from time-series observations of ${ }^{14} \mathrm{C}$ bicarbonate uptake. Mar Ecol Prog Ser 43:125-138

Gifford D, Fessenden L, Garrahan P, Martin E (1995) Grazing by microzooplankton and mesozooplankton in the high-latitude North Atlantic Ocean: spring versus summer dynamics. J Geophys Res 100:6665-6675

> Iluz D, Dishon G, Capuzzo E, Meeder E and others (2009) Short-term variability in primary productivity during a wind-driven diatom bloom in the Gulf of Eilat (Aqaba). Aquat Microb Ecol 56:205-215

Iturriaga R, Marra J (1988) Temporal and spatial variability of chroococcoid cyanobacteria Synechococcus spp. specific growth rates and their contribution to primary production in the Sargasso Sea. Mar Ecol Prog Ser 44: 175-181

Jackson GA (1983) Zooplankton grazing effects on ${ }^{14} \mathrm{C}$ based phytoplankton production measurements: a theoretical study. J Plank Res 5:83-94

> Joint IR, Pomroy AJ (1983) Production of picoplankton and small nanoplankton in the Celtic Sea. Mar Biol 77:19-27

Kim HC, Lee K, Choi W (2006) Contribution of phytoplankton and bacterial cells to the measured alkalinity of seawater. Limnol Oceanogr 51:331-338

Knoechel R, Kalff J (1976) Track autoradiography, a method for the determination of phytoplankton species productivity. Limnol Oceanogr 21:590-596

Landry MR, Hassett RP (1982) Estimating the grazing impact of marine microzooplankton. Mar Biol 67: $283-288$

Langdon C (1993) The significance of respiration in production measurements based on oxygen. ICES Mar Sci Symp (La Rochelle) 197:69-78 
Laws EA (1984) Improved estimates of phytoplankton carbon based on ${ }^{14} \mathrm{C}$ incorporation into chlorophyll a. J Theor Biol 110:425-434

Laws EA, Landry MR, Barber RT, Bender M, Campbell L, Dickson ML, Marra J (2000) Carbon cycling in primary production bottle incubations: inferences from grazing experiments and photosynthetic studies using ${ }^{14} \mathrm{C}$ and ${ }^{18} \mathrm{O}$ in the Arabian Sea. Deep-Sea Res II 47:1339-1352

Lessard EJ, Murrell MC (1998) Microzooplankton herbivory and phytoplankton growth in the northwestern Sargasso Sea. Aquat Microb Ecol 16:173-188

Li WKW (1994) Primary production of prochlorophytes, cyanobacteria, and eucaryotic ultraphytoplankton: measurements from flow cytometric sorting. Limnol Oceanogr 39:169-175

Li WKW, Dickie PM (1985) Growth of bacteria in seawater filtered through $0.2 \mu \mathrm{m}$ Nuclepore membranes: implications for dilution experiments. Mar Ecol Prog Ser 26:245-252

MacDonell MT, Hood MA (1982) Isolation and characterization of ultra-microbacteria from a Gulf Coast estuary. Appl Environ Microbiol 43:566-571

Marra J (2009) Net and gross productivity: weighing in with ${ }^{14} \mathrm{C}$. Aquat Microb Ecol 56:123-131

Marra J, Barber RT (2004) Phytoplankton and heterotrophic respiration in the surface layer of the ocean. Geophys

Editorial responsibility: Jonathan Cole,

Milbrook, New York, USA
Res Lett 31:L09314. doi:10.1029/2004GL019664

Parsons TR, Takahashi M, Hargrave B (1984) Biological oceanographic processes, 3rd edn. Pergamon, Oxford

Rivkin RB, Seliger HH (1981) Liquid scintillation counting for ${ }^{14} \mathrm{C}$ uptake of single algal cells isolated from natural samples. Limnol Oceanogr 26:780-785

Robinson C, Williams PJleB (2005) Respiration and its measurement in surface marine waters. In: del Giorgio $\mathrm{P}$, Williams PJleB (eds) Respiration in aquatic ecosystems. Oxford University Press, Oxford, p 147-179

Torrella F, Morita RY (1981) Microcultural study of bacterial size changes and microcolony and ultramicrocolony formation by heterotrophic bacteria in seawater. Appl Environ Microbiol 41:518-527

- Verity P (1985) Grazing, respiration, excretion, and growth rates of tintinnids. Limnol Oceanogr 30:1268-1282

Wilhelm SW, Suttle CA (1999) Viruses and nutrient cycles in the sea. BioScience 49:781-788

Worden AZ, Binder BJ (2003) Application of dilution experiments for measuring growth and mortality rates among Prochlorococcus and Synechococcus populations in oligotrophic environments. Aquat Microb Ecol 30:159-174

Zubkov MV, Tarran GA (2008) High bacterivory by the smallest phytoplankton in the North Atlantic Ocean. Nature 455:224-226

Submitted: April 27, 2011; Accepted: December 13, 2011 Proofs received from author(s): February 17, 2012 